\title{
A Focused Review on the Maximal Exercise Responses in Hypo- and Normobaric Hypoxia: Divergent Oxygen Uptake and Ventilation Responses
}

\author{
Benedikt Treml $^{1}{ }^{(\mathbb{D}}$, Hannes Gatterer ${ }^{2}{ }^{\mathbb{D}}$, Johannes Burtscher ${ }^{3}$, Axel Kleinsasser ${ }^{4, *}$ and \\ Martin Burtscher 5,6 (D) \\ 1 Department of General and Surgical Intensive Care, Medical University Innsbruck, 6020 Innsbruck, Austria; \\ benedikt.treml@tirol-kliniken.at \\ 2 Institute of Mountain Emergency Medicine, Eurac Research, 39100 Bolzano, Italy; hannes.gatterer@eurac.edu \\ 3 Institute of Sport Sciences, Synathlon, Uni-Centre, 1015 Lausanne, Switzerland; johannes.burtscher@unil.ch \\ 4 Postoperative Critical Care Unit, Department of Anesthesiology and Critical Care Medicine, \\ Medical University Innsbruck, 6020 Innsbruck, Austria \\ 5 Department of Sport Science, University of Innsbruck, 6020 Innsbruck, Austria; martin.burtscher@uibk.ac.at \\ 6 Austrian Society for Alpine and Mountain Medicine, 6020 Innsbruck, Austria \\ * Correspondence: axel.kleinsasser@tirol-kliniken.at; Tel.: +43-050504-80409
}

Received: 14 May 2020; Accepted: 15 July 2020; Published: 20 July 2020

\begin{abstract}
The literature suggests that acute hypobaric $(\mathrm{HH})$ and normobaric $(\mathrm{NH})$ hypoxia exposure elicits different physiological responses. Only limited information is available on whether maximal cardiorespiratory exercise test outcomes, performed on either the treadmill or the cycle ergometer, are affected differently by $\mathrm{NH}$ and $\mathrm{HH}$. A focused literature review was performed to identify relevant studies reporting cardiorespiratory responses in well-trained male athletes (individuals with a maximal oxygen uptake, $\mathrm{VO}_{2 \max }>50 \mathrm{~mL} / \mathrm{min} / \mathrm{kg}$ at sea level) to cycling or treadmill running in simulated acute $\mathrm{HH}$ or NH. Twenty-one studies were selected. The exercise tests in these studies were performed in $\mathrm{HH}(n=90)$ or $\mathrm{NH}(n=151)$ conditions, on a bicycle ergometer $(n=178)$ or on a treadmill $(n=63)$. Altitudes (simulated and terrestrial) varied between 2182 and $5400 \mathrm{~m}$. Analyses (based on weighted group means) revealed that the decline in $\mathrm{VO}_{2}$ max per $1000 \mathrm{~m}$ gain in altitude was more pronounced in acute $\mathrm{NH}$ vs. $\mathrm{HH}(-7.0 \pm 1.4 \%$ vs. $-5.6 \pm 0.9 \%)$. Maximal minute ventilation $\left(\mathrm{VE}_{\text {max }}\right)$ increased in acute $\mathrm{HH}$ but decreased in $\mathrm{NH}$ with increasing simulated altitude $(+1.9 \pm 0.9 \%$ vs. $-1.4 \pm 1.8 \%$ per $1000 \mathrm{~m}$ gain in altitude). Treadmill running in $\mathrm{HH}$ caused larger decreases in arterial oxygen saturation and heart rate than ergometer cycling in acute $\mathrm{HH}$, which was not the case in NH. These results indicate distinct differences between maximal cardiorespiratory responses to cycling and treadmill running in acute $\mathrm{NH}$ or $\mathrm{HH}$. Such differences should be considered when interpreting exercise test results and/or monitoring athletic training.
\end{abstract}

Keywords: exercise testing; normobaric; hypobaric; maximal oxygen uptake; maximal minute ventilation

\section{Introduction}

When Mexico City (2300 m above sea level) was chosen to host the 1968 Olympic Games, sports scientists and coaches were challenged with performance limitations and physiological responses to exercise in acute hypobaric hypoxia $(\mathrm{HH})$ [1-3]. Subsequently, there was a rise in scientific interest in evaluating the effects of acute normobaric hypoxia $(\mathrm{NH})$ on exercise performance and on physiological responses [4,5]. Today, some 50 years later, comparisons between acute $\mathrm{HH}$ and $\mathrm{NH}$ still remain scarce [6-8]. It has to be noted that during the acclimatization process (with subacute and chronic 
exposures to altitude/hypoxia) physiological responses change associated with improved exercise performance $[9,10]$.

A few years ago, Coppel and coworkers systematically reviewed the literature for physiological response differences between $\mathrm{HH}$ and $\mathrm{NH}$ [11]. This review and a more recent study [12] mainly focused on resting and submaximal exercise responses, with less emphasis on maximal exercise outcomes. Interestingly, most results indicated small differences in ventilatory parameters, however contrasting reports also exist [6-8]. Such divergent findings come as little surprise, as comparisons have often been affected by confounders such as the duration spent in hypoxia, temperature, and the humidity during exposure to hypoxia. Moreover, in some studies small sample sizes provide only limited statistical power $[11,13,14]$.

With regard to potential exercise performance differences between $\mathrm{HH}$ and $\mathrm{NH}$, the few existing comparative studies suggest a larger performance decline (e.g., time trial performance) in HH compared to NH [15]. Yet, little information is available on differences in physiological responses of athletes performing maximal exercise testing (i.e., incremental exercise test to exhaustion) in acute $\mathrm{HH}$ or $\mathrm{NH}$.

Therefore, the aim of the present review was to summarize selected findings of studies investigating maximal incremental exercise test outcomes of well-trained athletes acutely exposed to $\mathrm{HH}$ (simulated and terrestrial) or $\mathrm{NH}$.

\section{Materials and Methods}

A focused literature review was performed to identify relevant studies reporting cardiorespiratory responses of athletes performing cycling or treadmill running in acute $\mathrm{HH}$ or $\mathrm{NH}$. The literature search was performed in the following databases using a cut-off date of May 2019: Pubmed/Medline, Web of Science, Science direct, Scopus, and Sport Discus. The following keywords were used: $\mathrm{VO}_{2 \max }$ and acute hypoxia (or altitude) and athletes. Figure 1 displays a flow chart which depicts the selection process.

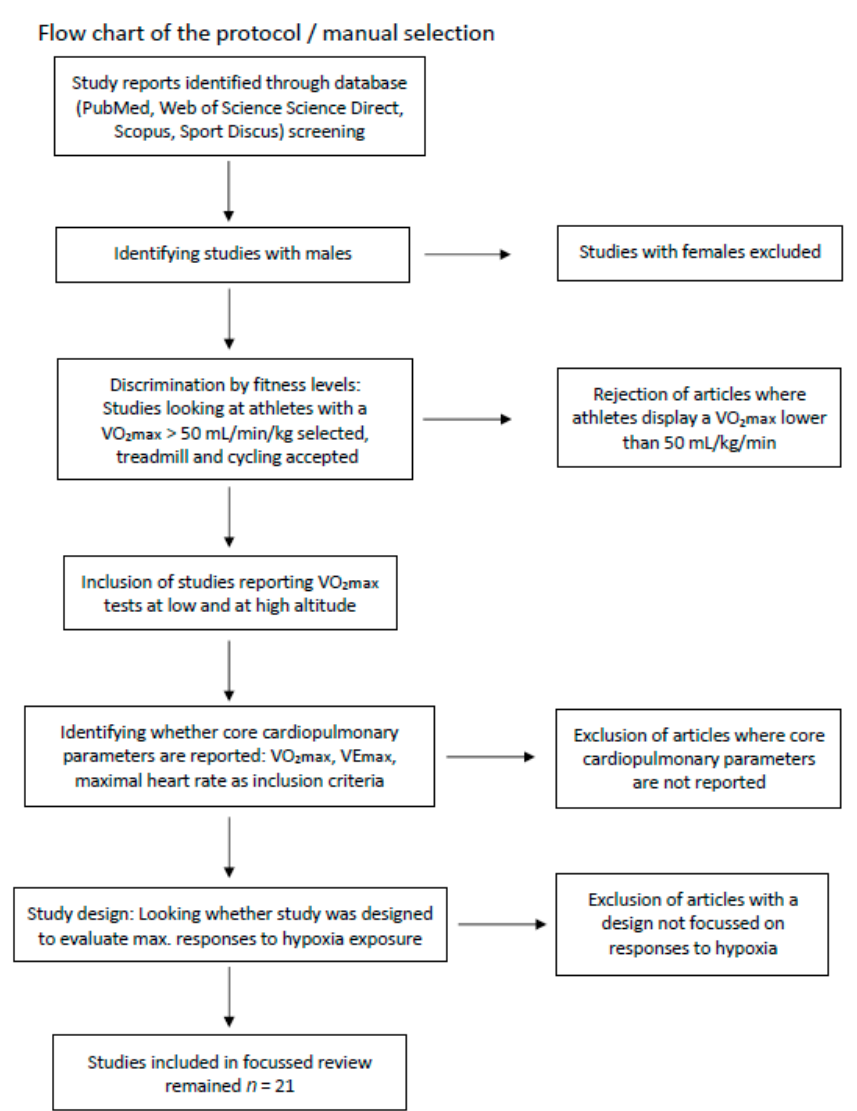

Figure 1. Flow chart of the protocol. 
Inclusion criteria were well-trained male athletes (due to insufficient data on females), not exposed to altitudes above $2000 \mathrm{~m}$ for at least one month prior to the study, with a maximal oxygen consumption $\left(\mathrm{VO}_{2 \max } \geq 50 \mathrm{~mL} / \mathrm{min} / \mathrm{kg}\right)$ at sea level and studies reporting the outcomes of maximal incremental exercise tests (cycling or treadmill) completed at sea level and after acute exposure (ie., within the first $2 \mathrm{~h}$, except one study where the ascent to real altitude lasted $8 \mathrm{~h} \mathrm{[9])} \mathrm{to} \mathrm{HH}$ (simulated and terrestrial) or $\mathrm{NH}$ at an altitude greater than $2000 \mathrm{~m}$. Exercise test outcomes included $\mathrm{VO}_{2 \max }$, maximal minute ventilation $\left(\mathrm{VE}_{\max }\right)$, peripheral oxygen saturation at maximal exercise $\left(\mathrm{SpO}_{2}\right)$, and maximal heart rate $\left(\mathrm{HR}_{\max }\right)$.

\section{Statistics}

Data are presented as weighted group means and standard deviation (SD) of the mean. To allow for comparisons between different altitudes, changes in cardiorespiratory variables from sea level to altitude were calculated as deltas per $1000 \mathrm{~m}$ gain in altitude. The association between continuous variables was assessed using simple linear regression analyses. Potential differences of cardiorespiratory responses to $\mathrm{HH}$ or $\mathrm{NH}$ during cycling or treadmill running were evaluated by calculation of effect sizes (ES, Cohen's d). An ES below 0.5 was considered to be small, 0.5 to 0.8 to be medium, and $>0.8$ to be large [16].

\section{Results}

A total of 21 studies were included, with 26 groups ( $n=241$ participants) evaluated at sea level and altitude (i.e., in NH or HH corresponding to altitude levels varying between 2182 and $5400 \mathrm{~m}$ ). Out of 26 groups, $10(n=90)$ were performed in $\mathrm{HH}[9,17-23]$ (all in hypobaric chambers, except one which was performed at real altitude [9]), and $16(n=151)$ in $\mathrm{NH}$ [24-34]. Baseline characteristics of the groups included and the general physiological responses to maximal exercise testing at altitude are shown in Table 1.

Table 1. Characteristics of the studies included in the analysis.

\begin{tabular}{|c|c|c|c|c|c|c|c|c|}
\hline Reference & Participants & $\begin{array}{l}\mathrm{VO}_{2 \max } \text { at } \\
\text { Sea Level }\end{array}$ & $\begin{array}{l}\text { Altitude or } \\
\text { Equivalent }\end{array}$ & $\begin{array}{c}\text { Hypoxia } \\
\text { Condition }\end{array}$ & $\begin{array}{c}\text { Baro-Metric } \\
\text { Pressure }\end{array}$ & $\mathrm{F}_{\mathrm{i}} \mathrm{O}_{2}$ & $\begin{array}{l}\text { Exercise } \\
\text { Mode }\end{array}$ & $\begin{array}{l}\mathrm{VO}_{2 \max } \text { at } \\
\text { Altitude }\end{array}$ \\
\hline & (number) & $(\mathrm{mL} / \mathrm{min} / \mathrm{kg})$ & (m) & & (mmHg) & $(\%)$ & & $(\mathrm{mL} / \mathrm{min} / \mathrm{kg})$ \\
\hline $\begin{array}{l}\text { Benoit et al. } \\
\text { (2003) [24] }\end{array}$ & 12 & 64.2 & 5400 & $\mathrm{NH}$ & & 10.4 & cycling & 36.0 \\
\hline $\begin{array}{l}\text { Benoit et al. } \\
\text { (2003) [24] }\end{array}$ & 17 & 50.8 & 5400 & $\mathrm{NH}$ & & 10.4 & cycling & 31.4 \\
\hline $\begin{array}{l}\text { Ferretti et al. } \\
\text { (1997) [25] }\end{array}$ & 5 & 62.1 & 2182 & $\mathrm{NH}$ & & 16.0 & cycling & 53.4 \\
\hline $\begin{array}{l}\text { Ferretti et al. } \\
\text { (1997) [25] }\end{array}$ & 5 & 62.1 & 4966 & $\mathrm{NH}$ & & 11.0 & cycling & 35.6 \\
\hline $\begin{array}{l}\text { Friedmann et al. } \\
\text { (2007) [26] }\end{array}$ & 20 & 68.0 & 2682 & $\mathrm{NH}$ & & 15.0 & treadmill & 53.1 \\
\hline $\begin{array}{l}\text { Fulco et al. } \\
\text { (1988) [19] }\end{array}$ & 7 & 50.1 & 4300 & $\mathrm{HH}(\mathrm{HC})$ & 446 & & cycling & 37.2 \\
\hline $\begin{array}{l}\text { Heubert et al. } \\
\text { (2005) [28] }\end{array}$ & 9 & 62.7 & 2500 & $\mathrm{NH}$ & & 16.0 & cycling & 53.6 \\
\hline $\begin{array}{l}\text { Horstman et al. } \\
\quad(1980)[9]\end{array}$ & 9 & 51.0 & 4300 & $\mathrm{HH}(\mathrm{TA})$ & 460 & & treadmill & 35.0 \\
\hline $\begin{array}{l}\text { Koistinen et al. } \\
\text { (1995) [20] }\end{array}$ & 12 & 57.4 & 3200 & $\mathrm{HH}(\mathrm{HC})$ & 520 & & cycling & 46.6 \\
\hline $\begin{array}{l}\text { Lawler et al. } \\
\text { (1988) [29] }\end{array}$ & 7 & 65.0 & 3207 & $\mathrm{NH}$ & & 14.0 & cycling & 51.1 \\
\hline $\begin{array}{l}\text { Martin et al. } \\
\text { (1993) [30] }\end{array}$ & 8 & 67.2 & 3760 & $\mathrm{NH}$ & & 13.0 & cycling & 49.7 \\
\hline $\begin{array}{l}\text { Mollard et al. } \\
\text { (2007) [31] }\end{array}$ & 8 & 65.5 & 2479 & $\mathrm{NH}$ & & 15.4 & cycling & 57.7 \\
\hline $\begin{array}{l}\text { Mollard et al. } \\
\text { (2007) [31] }\end{array}$ & 8 & 65.5 & 4527 & $\mathrm{NH}$ & & 11.7 & cycling & 46.4 \\
\hline $\begin{array}{l}\text { Ofner et al. } \\
\text { (2014) [32] }\end{array}$ & 10 & 51.0 & 3500 & $\mathrm{NH}$ & & 14.0 & cycling & 42.5 \\
\hline
\end{tabular}


Table 1. Cont.

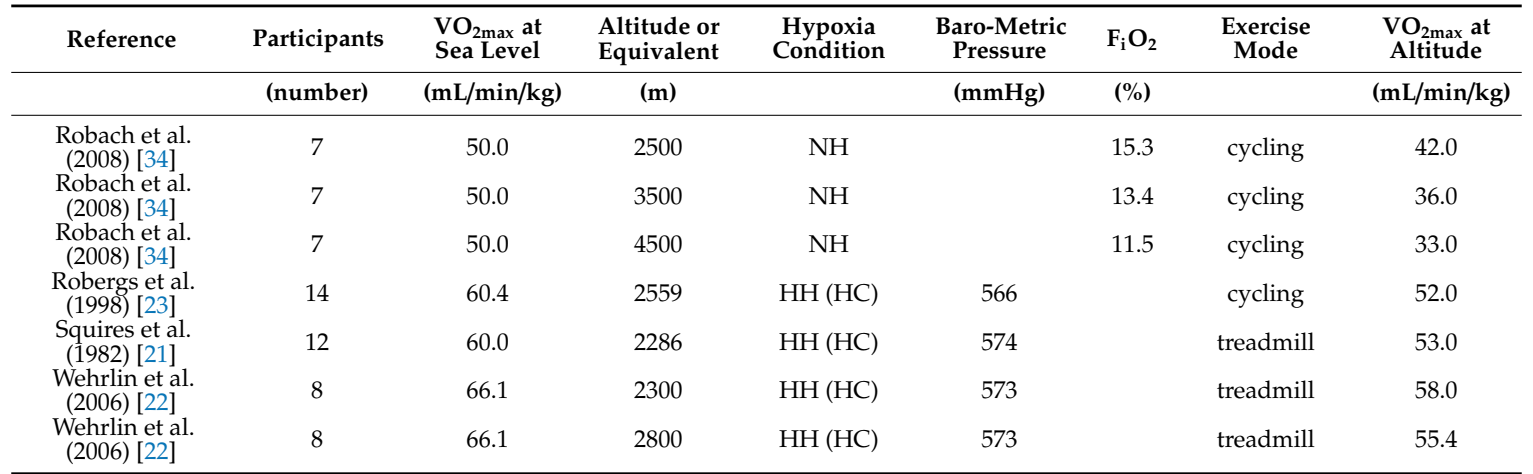

Maximal oxygen uptake, $\mathrm{VO}_{2 m a x}$; fraction of inspired oxygen, $\mathrm{F}_{\mathrm{i}} \mathrm{O}_{2}$; hypobaric hypoxia, $\mathrm{HH}$ (HC, hypobaric chamber;

TA, terrestrial altitude); normobaric hypoxia, NH.

Figure 2 depicts the salient findings of this focused review in regard to divergent oxygen uptake and ventilation responses in hypo- and normobaric hypoxia.

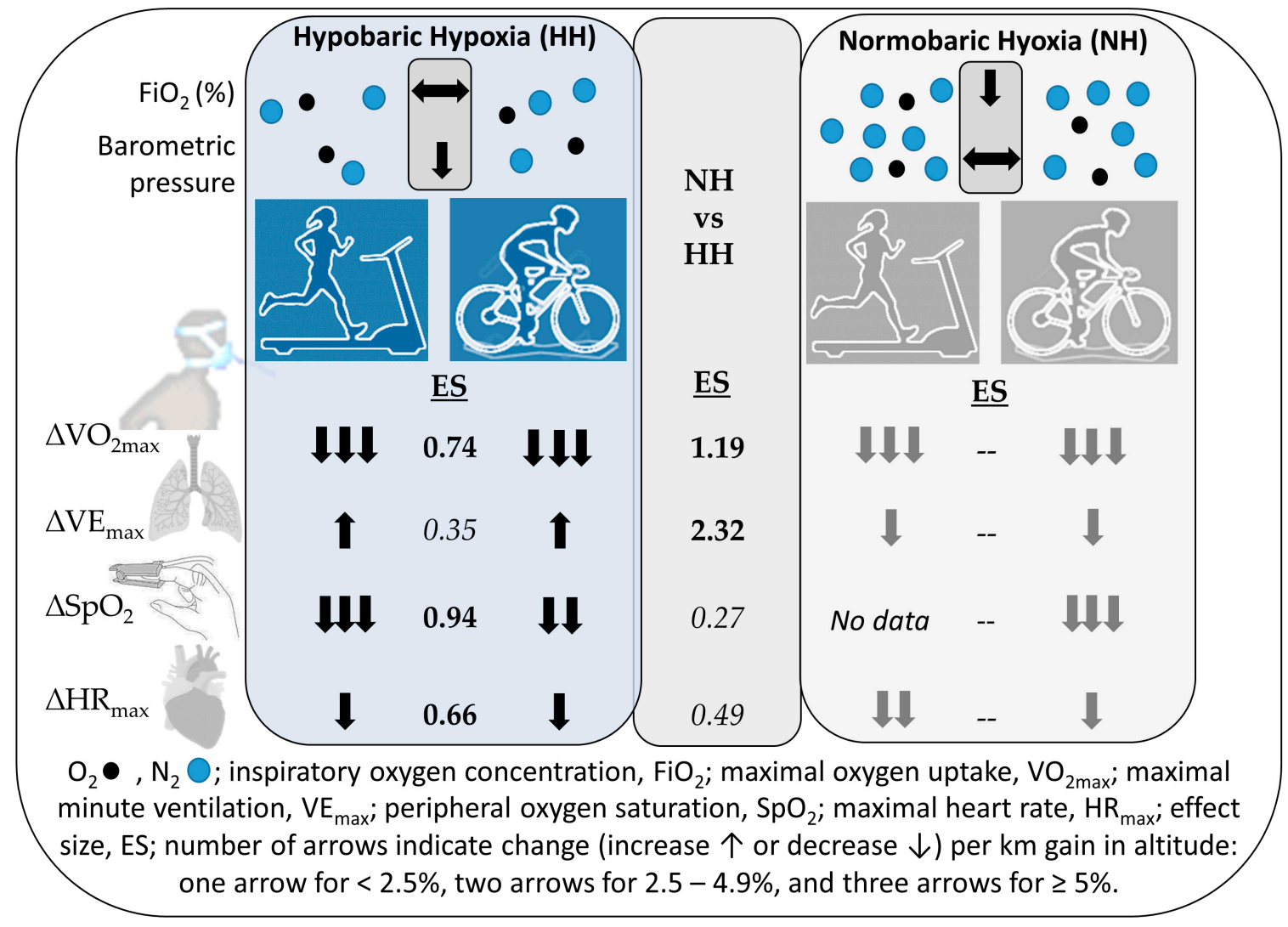

Figure 2. Schematic presentation of the key findings.

Effect sizes for differences between cycling and treadmill running could not be calculated because there was only one study evaluating treadmill running.

Table 2 displays the characteristics of the study participants of the studies included, separated by the $\mathrm{HH}$ and $\mathrm{NH}$ condition.

Table 3 depicts the differences between $\mathrm{HH}$ and $\mathrm{NH}$ per $1000 \mathrm{~m}$ of altitude gain separated by exercise task. 
Table 2. Characteristics of study participants of the included $\mathrm{HH}$ and $\mathrm{NH}$ studies.

\begin{tabular}{ccccccc}
\hline & \multicolumn{2}{c}{ All } & \multicolumn{5}{c}{ Divided by Exercise Mode } \\
\hline Variable & $\boldsymbol{n}$ & \multicolumn{4}{c}{ Hypobaric Hypoxia Studies } \\
Cycling Exercise & $\boldsymbol{n}$ & Treadmill Running \\
\hline Age (yr) & 90 & $25.7 \pm 3.7$ & 47 & $26.1 \pm 4.3$ & 43 & $25.3 \pm 3.0$ \\
Weight (kg) & 90 & $73.6 \pm 2.5$ & 47 & $73.5 \pm 1.2$ & 43 & $73.7 \pm 3.4$ \\
Height (cm) & 90 & $178.8 \pm 2.0$ & 47 & $178.1 \pm 2.1$ & 43 & $179.5 \pm 1.5$ \\
Altitude level (m) & 90 & $3117 \pm 755$ & 47 & $3144 \pm 577$ & 43 & $3087 \pm 918$ \\
& & \multicolumn{2}{c}{ Normobaric Hypoxia Studies } & & \\
Age (yr) & 147 & $25.2 \pm 3.4$ & 129 & $26.0 \pm 2.9$ & 18 & $24.1 \pm 4.1 *$ \\
Weight (kg) & 147 & $72.6 \pm 5.2$ & 129 & $72.9 \pm 5.5$ & 18 & $71.2 \pm 6.5$ \\
Height (cm) & 147 & $178.7 \pm 2.7$ & 129 & $178.2 \pm 2.5$ & 18 & $182.1 \pm 5.9$ \\
Altitude level (m) & 147 & $3678 \pm 1095$ & 129 & $3830 \pm 1099$ & 18 & 2682 \\
\hline
\end{tabular}

Maximal oxygen uptake, $\mathrm{VO}_{2 \max }$; oxygen saturation, $\mathrm{SpO}_{2}$; maximal minute ventilation, $\mathrm{VE}_{\max }$; gas volumina are expressed as body temperature pressure saturated (BTPS). ${ }^{*}$ Standard deviation (SD) taken from the respective study.

The data show that in $\mathrm{NH}, \mathrm{VO}_{2 \max }$, combined for cycling and treadmill running, is reduced to a larger extent compared to $\mathrm{HH}$ (ES: 1.19). $\mathrm{VE}_{\max }$, combined for cycling and treadmill running, is slightly increased in $\mathrm{HH}$, whereas it is reduced in $\mathrm{NH}$ (ES: 2.32); small to medium ES were detected for $\mathrm{SpO}_{2}$ (ES: 0.27) and $\mathrm{HR}_{\max }$ (ES: 0.49) between conditions. Interestingly, when converting $\mathrm{VE}_{\max }$ from body temperature pressure saturated (BTPS) to standard temperature pressure dry (STPD), VE $\max$ values (STPD) were the same in $\mathrm{NH}$ and $\mathrm{HH}$. Moderate to large effects were found between cycling and treadmill running in $\mathrm{HH}$, indicating that $\mathrm{VO}_{2 \max }$ (ES: 0.74), $\mathrm{SpO}_{2}$ (ES: 0.94) and $\mathrm{HR}_{\max }$ (ES: 0.66) are more affected during treadmill running compared to cycling, although $\mathrm{VE}_{\max }$ was slightly higher during treadmill running (ES: 0.35).

Furthermore, the data show a similar slope between changes in $\mathrm{VO}_{2 \max }$ and $\mathrm{SpO}_{2 \max }$ (Figure 3) and $\mathrm{VE}_{\max }$ and $\mathrm{HR}_{\max }$ (Figure 4) with gain in altitude, but at different levels for $\mathrm{NH}$ and $\mathrm{HH}$.

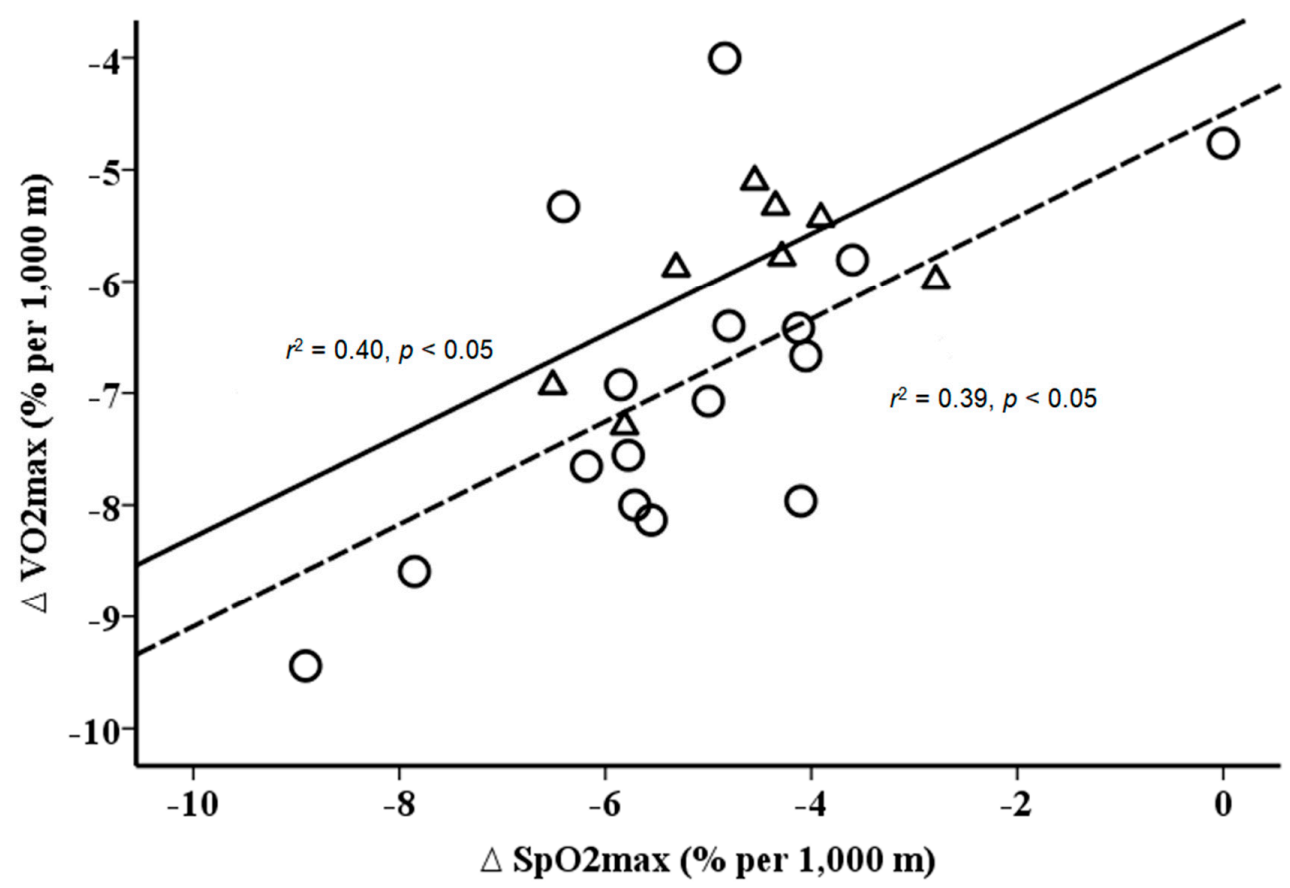

Figure 3. Relationship between changes (\%) in peripheral oxygen saturation during maximal exercise $\left(\mathrm{SpO}_{2 \mathrm{max}}\right)$ and maximal oxygen uptake $\left(\mathrm{VO}_{2 \mathrm{max}}\right)$ per $1 \mathrm{~km}$ gain in altitude. Solid line (triangles) for hypobaric hypoxia $\left(r^{2}=0.40, p<0.05\right)$ and dashed line (circles) for normobaric hypoxia $\left(r^{2}=0.39\right.$, $p<0.05)$. Delta values are calculated as $\mathrm{HH} / \mathrm{NH}$ values minus sea level values. 
Table 3. Changes for each $1000 \mathrm{~m}$ altitude climb separately shown for altitude conditions and exercise mode.

\begin{tabular}{|c|c|c|c|c|c|c|c|c|c|c|c|c|}
\hline \multirow[b]{2}{*}{ Variable } & \multicolumn{2}{|r|}{$\mathbf{H H}$} & \multicolumn{2}{|r|}{ NH } & \multicolumn{4}{|c|}{ HH } & \multicolumn{4}{|c|}{ NH } \\
\hline & $n$ & $\begin{array}{l}\text { Cycling + } \\
\text { Treadmill }\end{array}$ & $n$ & $\begin{array}{l}\text { Cycling + } \\
\text { Treadmill }\end{array}$ & $n$ & $\begin{array}{l}\text { Cycling } \\
\text { Exercise }\end{array}$ & $n$ & $\begin{array}{l}\text { Treadmill } \\
\text { Running }\end{array}$ & $n$ & $\begin{array}{l}\text { Cycling } \\
\text { Exercise }\end{array}$ & $n$ & $\begin{array}{l}\text { Treadmill } \\
\text { Running }\end{array}$ \\
\hline $\begin{array}{c}\Delta \mathrm{VO}_{2 \max } \\
(\% / \mathrm{km})\end{array}$ & $\begin{array}{c}9 \\
90\end{array}$ & $-5.6 \pm 0.9$ & $\begin{array}{c}18 \\
151\end{array}$ & $-7.0 \pm 1.4^{\mathrm{a}}$ & $\begin{array}{c}4 \\
47\end{array}$ & $-5.3 \pm 0.7$ & $\begin{array}{c}5 \\
43\end{array}$ & $-5.9 \pm 0.9^{b}$ & $\begin{array}{c}17 \\
131\end{array}$ & $-6.8 \pm 1.4$ & $\begin{array}{c}1 \\
20\end{array}$ & $-8.1 \pm 0.0$ \\
\hline $\begin{array}{l}\Delta \mathrm{VE}_{\max } \\
(\% / \mathrm{km})\end{array}$ & $\begin{array}{c}9 \\
90\end{array}$ & $1.9 \pm 0.9$ & $\begin{array}{c}15 \\
132\end{array}$ & $-1.4 \pm 1.8^{\mathrm{a}}$ & $\begin{array}{c}4 \\
47\end{array}$ & $1.8 \pm 1.1$ & $\begin{array}{c}5 \\
43\end{array}$ & $2.1 \pm 0.5^{c}$ & $\begin{array}{c}14 \\
112\end{array}$ & $-1.6 \pm 1.9$ & $\begin{array}{c}1 \\
20\end{array}$ & $-0.2 \pm 0.0$ \\
\hline $\begin{array}{l}\Delta \mathrm{SpO}_{2} \\
(\% / \mathrm{km})\end{array}$ & $\begin{array}{c}8 \\
79\end{array}$ & $-4.6 \pm 1.0$ & $\begin{array}{c}17 \\
131\end{array}$ & $-5.0 \pm 1.8^{c}$ & $\begin{array}{c}3 \\
36\end{array}$ & $-4.2 \pm 0.9$ & $\begin{array}{c}5 \\
43\end{array}$ & $-5.0 \pm 0.8^{\mathrm{a}}$ & $\begin{array}{c}17 \\
131\end{array}$ & $-5.0 \pm 1.9$ & / & I \\
\hline $\begin{array}{l}\Delta \mathrm{HR}_{\max } \\
(\% / \mathrm{km})\end{array}$ & $\begin{array}{c}9 \\
90\end{array}$ & $-1.6 \pm 0.6$ & $\begin{array}{c}13 \\
117\end{array}$ & $-2.1 \pm 1.3^{c}$ & $\begin{array}{c}4 \\
47\end{array}$ & $-1.4 \pm 0.7$ & $\begin{array}{c}5 \\
43\end{array}$ & $-1.8 \pm 0.5^{b}$ & $\begin{array}{l}12 \\
97\end{array}$ & $-2.0 \pm 1.3$ & $\begin{array}{c}1 \\
20\end{array}$ & $-3.0 \pm 0.0$ \\
\hline
\end{tabular}

Heart rate, $\mathrm{HR}$; hypobaric hypoxia, $\mathrm{HH}$; maximal oxygen uptake, $\mathrm{VO}_{2 \max }$; normobaric hypoxia, $\mathrm{NH}$; oxygen saturation, $\mathrm{SpO} \mathrm{O}_{2}$; ventilation, $\mathrm{VE}$. Delta values are calculated as $\mathrm{HH} / \mathrm{NH}$ values minus sea level values. $n$ indicates the number of included studies (upper number) and the number of participants involved (lower number). ${ }^{a}$, ${ }^{b}$ and ${ }^{c}$ indicate large, medium, and small effect size respectively. ES for treadmill running in NH could not be calculated because only one study was available. 


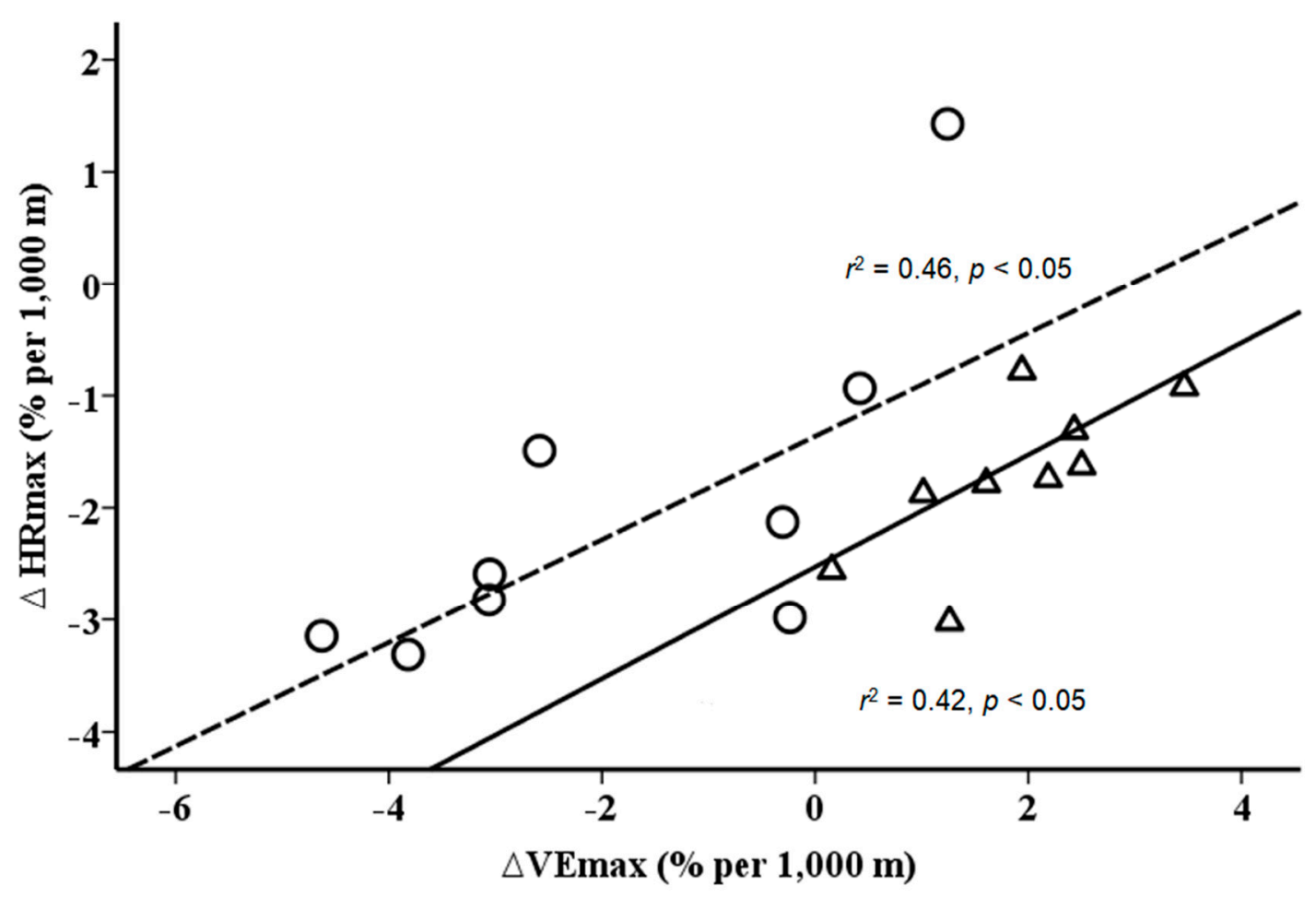

Figure 4. Relationship between changes (\%) in maximal minute ventilation $\left(\mathrm{VE}_{\max }\right)$ and maximal heart rates $\left(\mathrm{HR}_{\max }\right)$ per $1 \mathrm{~km}$ gain in altitude. Solid line (triangles) for hypobaric hypoxia $\left(r^{2}=0.46, p<0.05\right)$ and dashed line (circles) for normobaric hypoxia $\left(r^{2}=0.42, p<0.05\right)$. Delta values are calculated as $\mathrm{HH} / \mathrm{NH}$ values minus sea level values.

\section{Discussion}

The main outcomes of the present literature review are that (for male athletes) the $\mathrm{VO}_{2 \max }$ decline is larger in $\mathrm{NH}$ as compared to $\mathrm{HH}$ (simulated and terrestrial) and that $\mathrm{VE}_{\max }$ slightly increases in $\mathrm{HH}$ whereas it is reduced in $\mathrm{NH}$. Additionally, for each $1000 \mathrm{~m}$ of altitude gain in $\mathrm{HH}$ (simulated and terrestrial), $\mathrm{VO}_{2 \max }$ during treadmill running seems to be more depressed compared to cycling. Furthermore, during treadmill running in $\mathrm{HH}$ (simulated and terrestrial), when compared to cycling, a larger $\mathrm{SpO}_{2 \max }$ and $\mathrm{HR}_{\max }$ decrease per $1000 \mathrm{~m}$ of altitude gain was found.

The $\mathrm{VO}_{2 \max }$ reduction and the increase of $\mathrm{VE}_{\max }$ at altitude are well documented [1,25,35-37]. It is also known that $\mathrm{VO}_{2 \max }$ is reduced in both acute $\mathrm{NH}[25,27-30,32-34,38,39]$ and $\mathrm{HH}[9,17-23]$ conditions. Yet, information on specific $\mathrm{VO}_{2 \max }$ differences between acute $\mathrm{NH}$ and $\mathrm{HH}$ in trained individuals is still lacking.

Previous work comparing differences between cardiorespiratory responses in acute $\mathrm{HH}$ and $\mathrm{NH}$ focused primarily on resting and submaximal exercise conditions [6-8,11,12,40]. Results of a recent meta-analysis (primarily performed on studies investigating resting conditions) indicate differences in variables related to $\mathrm{VE}, \mathrm{NO}$, fluid retention, and acute mountain sickness (AMS) associated factors between acute $\mathrm{HH}$ and $\mathrm{NH}$ [11]. The existence of such differences is also supported by Saugy et al. and Beidleman et al. who found differences in time trial performance between acute $\mathrm{HH}$ and $\mathrm{NH}$, with greater performance losses during acute $\mathrm{HH}$ exposure [15,41]. In the study of Saugy et al. this was thought to be a result of a lower $\mathrm{SpO}_{2}$ in acute $\mathrm{HH}$ compared to $\mathrm{NH}$, which was not reported by Beidleman et al. Both studies, however, did not determine cardiorespiratory responses at maximal exercise, which is of particular interest from an athletic training and testing perspective. To bridge this knowledge gap, the present analyses focused primarily on differences between acute $\mathrm{NH}$ and $\mathrm{HH}$ at maximal exercise. Larger $\mathrm{VE}_{\max }$ responses in acute $\mathrm{HH}$ compared to $\mathrm{NH}$ (at comparable simulated altitude levels) may be expected due to the lower air density in $\mathrm{HH}$ [35]. Higher $\mathrm{VE}_{\max }$ in acute $\mathrm{HH}$ compared to NH (during running) was recently demonstrated by Ogawa et al., which is likely due 
to a lower flow resistance in the airways [42]. When linking the reduced $\mathrm{VE}_{\max }$ responses to the higher $\mathrm{VO}_{2 \max }$ decline in $\mathrm{NH}$ compared to $\mathrm{HH}$, the lower $\mathrm{VE}_{\max }$ at reduced exercise performance has to be emphasized. This complicates the interpretation of $\mathrm{VE}_{\max }$ changes when exercise is not performed at the same level of hypoxia in acute $\mathrm{HH}$ and NH. Distinct breathing patterns (i.e., tidal volume and breathing frequency) in acute $\mathrm{HH}$ and $\mathrm{NH}$ [43-45] might have influenced the central motor drive [46] and $\mathrm{VO}_{2 \max }$. Irrespective of these proposed mechanisms, it should be mentioned that Pugh demonstrated 50 years ago that exercise VE expressed as STPD remained unchanged at various altitudes at least up to $5800 \mathrm{~m}$, while exercise VE expressed as BTPS (as is usually done) increased with the gain in altitude in a non-linear fashion [35]. Accordingly, similar $\mathrm{VE}_{\max }$ values (STPD) in HH and $\mathrm{NH}$ were found when converting the $\mathrm{VE}_{\max }$ values of the included studies from BTPS to STPD.

It is worth noting that a similar decrease of $\mathrm{SpO}_{2}$ at maximal exercise-despite different $\mathrm{VE}_{\max }$ responses-was related to a more reduced $\mathrm{VO}_{2 \max }$ in acute $\mathrm{NH}$ than in $\mathrm{HH}$. Arterial oxygen desaturation has been shown to be linked to the decrease in $\mathrm{HR}_{\max }$. Decreases in $\mathrm{HR}_{\max }$, moreover might be influenced by the activity of the parasympathetic system or by myocardial electrophysiological and central factors [47-49]. Analyses of the results of the studies included revealed a similar relationship in acute $\mathrm{NH}\left(r^{2}=0.8, p<0.05\right)$ but not in $\mathrm{HH}$. Whether this association is actually more important in acute $\mathrm{NH}$ than in $\mathrm{HH}$ has yet to be established. A higher $\mathrm{SpO}_{2}$ might be related to a higher performance level. Overall, it seems that there is a complex interplay between different respiratory, metabolic and autonomic regulations in $\mathrm{NH}$ and $\mathrm{HH}$ that might explain the observed differences in $\mathrm{VO}_{2 \max }$.

Beside the general responses of performing exercise in acute $\mathrm{HH}$ and $\mathrm{NH}$, we found some small differences in the maximal cardiorespiratory responses between cycling and treadmill running. These differences are not straightforward to explain. Gavin and Stager demonstrated a more pronounced exercise-induced hypoxaemia (in normoxia) during cycling compared to running, potentially indicating a similar association in HH [50]. Generally, breathing patterns are different between cycling and running [51], potentially explaining the differences observed. Moreover, there is one excellent review specifically dealing with physiological differences between cycling and running [52]. Although differences will largely depend on the sport and training practiced, different responses to maximal exercise performed in normoxia, as outlined in that review [52], may help to explain such differences in hypoxia, as demonstrated in the present review. Millet and colleagues reported the following differences [52]. Whereas runners usually achieve higher $\mathrm{VO}_{2 \max }$ values, in cyclists those values seem not to be different between cycling and treadmill running. Maximal heart rates have been found to be about $5 \%$ higher when derived from incremental treadmill running compared to cycling (at least in not well-trained individuals). Moreover, the delta efficiency was shown to be higher in running. Exercise ventilation is likely influenced by different pulmonary mechanics between cycling and treadmill running and may be more impaired in cycling than running. With regard to desaturation during maximal exercise, triathletes at least showed more pronounced desaturation (lower $\mathrm{SpO}_{2}$ values) during running than cycling.

In the present literature review, the focus was on maximal values during exercise testing. These results to some extent contrast those found during submaximal exercise. For instance, Netzer et al. found lower $\mathrm{SpO}_{2}$ and a higher $\mathrm{HR}$ values during exercise in $\mathrm{HH}$ compared to $\mathrm{NH}$ [53]. Similar to the present findings, Faiss et al. reported no differences in $\mathrm{SpO}_{2}$ values between conditions during cycling, yet VE was lower in acute HH compared to NH [45]. Similar to this, Beidleman et al. and Basualto-Alarcón et al. reported no effect of the type of condition on $\mathrm{SpO}_{2}$ and $\mathrm{HR}[6,15]$, yet exercise performance was more affected under acute HH conditions [15]. The differences in VE between submaximal and maximal exercise in acute $\mathrm{NH}$ and $\mathrm{HH}$ seem reasonable; the lower air density may allow a lower VE at submaximal exercise and a higher one at maximal exercise. With regard to exercise performance and $\mathrm{SpO}_{2}$, the factors discussed above (e.g., metabolic and autonomic regulation) may explain some of the differences, yet this has to be established in future studies. 


\section{Limitations}

Some limitations of the present analyses have to be acknowledged. First, we are aware that there have been a multitude of studies performing maximal incremental exercise testing in acute hypoxia. Yet, as the focus of those studies was on other topics, our literature search strategy might not have identified them. Nonetheless, the number of included studies and participants seems acceptable to allow the preliminary conclusions here presented. Second, analyses of data in this literature review have been performed on the basis of group averages, allowing effect sizes to be calculated. Third, we were not able to evaluate potential gender differences, as there are only very few studies including female athletes. Fourth, we must acknowledge that the validity of any comparison between acute $\mathrm{NH}$ and $\mathrm{HH}$ conditions depends on the accuracy of the calculation of the equivalent altitude, as was recently addressed in detail [40,54]. The calculation may depend on the location of the experimental site, the ambient temperature, or the degree of hygrometry and the official standard used [54]. In the present analysis, these factors were disregarded. Nonetheless, from a practical/real life perspective, our analysis seems valid, yet we urge others to perform studies designed to specifically address this issue (e.g., cross over studies with matched $\mathrm{PiO}_{2}$ ). In addition, available information does not allow whether participants were blinded in $\mathrm{NH}$ or not to be assessed with confidence. Thus, a potential placebo effect cannot be excluded. Finally, potential confounding may arise from the use of different test protocols and different measurement devices. Overall, this is the first review taking into account a reasonable number of studies evaluating cardiorespiratory exercise responses to maximal incremental exercise testing (treadmill and cycle ergometry) in trained individuals at sea level and in acute $\mathrm{HH}$ (simulated and terrestrial) and NH as well.

\section{Conclusions}

The analyses presented indicate that in well-trained men performing maximal exercise tasks, $\mathrm{VO}_{2 \max }$ declines to a larger extent in acute $\mathrm{NH}$ compared to $\mathrm{HH}$, which goes along a higher $\mathrm{VE}_{\text {max }}$ in $\mathrm{HH}$. Treadmill running in acute $\mathrm{HH}$ caused more pronounced depressions of $\mathrm{VO}_{2 \text { max }}, \mathrm{SpO}_{2}$, and $\mathrm{HR}_{\text {max }}$ compared to cycling exercise. These findings may have practical and clinical implications when interpreting exercise test results in acute $\mathrm{NH}$ and $\mathrm{HH}$, and could inspire the design of according studies, but are also of novel applications in exercising in hypoxia.

Future studies will focus on potential sex and age differences between responses to acute $\mathrm{NH}$ and $\mathrm{HH}$, but will also evaluate changes occurring with acclimatization.

Author Contributions: Conceptualization, M.B. and H.G.; methodology, M.B.; software, J.B.; validation, M.B., J.B., H.G., A.K. and B.T.; formal analysis, M.B. and J.B.; investigation, J.B.; resources, M.B.; data curation, M.B.; writing-original draft preparation, M.B., H.G., J.B., A.K. and B.T.; writing-review and editing, M.B., J.B., H.G., A.K. and B.T.; visualization, J.B.; supervision, M.B.; project administration, M.B.; All authors have read and agreed to the published version of the manuscript.

Funding: This research received no external funding.

Conflicts of Interest: The authors declare no conflict of interest.

\section{References}

1. Pugh, L.G. Athletes at altitude. J. Physiol. 1967, 192, 619-646. [CrossRef] [PubMed]

2. Daniels, J.; Oldridge, N. The effects of alternate exposure to altitude and sea level on world-class middle-distance runners. Med. Sci. Sports 1970, 2, 107-112. [CrossRef] [PubMed]

3. Mellerowicz, H.; Meller, W.; Wowerier, J.; Zerdick, J.; Ketusinh, O.; Kral, B.; Heepe, W. Comparative studies on the effect of high altitude training on permanent performance at lower altitudes. Schweiz. Z. Sportmed. 1971, (Suppl. 5-17). [PubMed]

4. Hammond, M.D.; Gale, G.E.; Kapitan, K.S.; Ries, A.; Wagner, P.D. Pulmonary gas exchange in humans during normobaric hypoxic exercise. J. Appl. Physiol. 1986, 61, 1749-1757. [CrossRef] [PubMed] 
5. Schmidt, W.; Eckardt, K.U.; Hilgendorf, A.; Strauch, S.; Bauer, C. Effects of maximal and submaximal exercise under normoxic and hypoxic conditions on serum erythropoietin level. Int. J. Sports Med. 1991, 12, 457-461. [CrossRef] [PubMed]

6. Basualto-Alarcón, C.; Rodas, G.; Galilea, P.A.; Riera, J.; Pagés, T.; Ricart, A.; Torrella, J.R.; Behn, C.; Viscor, G. Cardiorespiratory parameters during submaximal exercise under acute exposure to normobaric and hypobaric hypoxia. Apunts. Med. Esport 2012, 47, 65-72.

7. Richard, N.A.; Sahota, I.S.; Widmer, N.; Ferguson, S.; Sheel, A.W.; Koehle, M.S. Acute mountain sickness, chemosensitivity, and cardiorespiratory responses in humans exposed to hypobaric and normobaric hypoxia. J. Appl. Physiol. 2014, 116, 945-952. [CrossRef]

8. Woods, D.R.; O’Hara, J.P.; Boos, C.J.; Hodkinson, P.D.; Tsakirides, C.; Hill, N.E.; Jose, D.; Hawkins, A.; Phillipson, K.; Hazlerigg, A.; et al. Markers of physiological stress during exercise under conditions of normoxia, normobaric hypoxia, hypobaric hypoxia, and genuine high altitude. Eur. J. Appl. Physiol. 2017, 117, 893-900. [CrossRef]

9. Horstman, D.; Weiskopf, R.; Jackson, R.E. Work capacity during 3-wk sojourn at $4300 \mathrm{~m}$ : Effects of relative polycythemia. J. Appl. Physiol. Respir. Environ. Exerc. Physiol. 1980, 49, 311-318. [PubMed]

10. Burtscher, M.; Niedermeier, M.; Burtscher, J.; Pesta, D.; Suchy, J.; Strasser, B. Preparation for Endurance Competitions at Altitude: Physiological, Psychological, Dietary and Coaching Aspects. A Narrative Review. Front. Physiol. 2018, 9, 1504. [CrossRef]

11. Coppel, J.; Hennis, P.; Gilbert-Kawai, E.; Grocott, M.P. The physiological effects of hypobaric hypoxia versus normobaric hypoxia: A systematic review of crossover trials. Extrem. Physiol. Med. 2015, 4, 2. [CrossRef] [PubMed]

12. Boos, C.J.; O’Hara, J.P.; Mellor, A.; Hodkinson, P.D.; Tsakirides, C.; Reeve, N.; Gallagher, L.; Green, N.D.; Woods, D.R. A Four-Way Comparison of Cardiac Function with Normobaric Normoxia, Normobaric Hypoxia, Hypobaric Hypoxia and Genuine High Altitude. PLoS ONE 2016, 11, e0152868. [CrossRef] [PubMed]

13. Viscor, G.; Torrella, J.R.; Corral, L.; Ricart, A.; Javierre, C.; Pages, T.; Ventura, J.L. Physiological and Biological Responses to Short-Term Intermittent Hypobaric Hypoxia Exposure: From Sports and Mountain Medicine to New Biomedical Applications. Front. Physiol. 2018, 9, 339. [CrossRef] [PubMed]

14. Debevec, T.; Millet, G.P. Discerning normobaric and hypobaric hypoxia: Significance of exposure duration. J. Appl. Physiol. 2014, 116, 1255. [CrossRef]

15. Beidleman, B.A.; Fulco, C.S.; Staab, J.E.; Andrew, S.P.; Muza, S.R. Cycling performance decrement is greater in hypobaric versus normobaric hypoxia. Extrem. Physiol. Med. 2014, 3, 8. [CrossRef]

16. Cohen, J. Statistical Power Analysis for the Behavioral Sciences, 2nd ed.; Lawrence Erlbaum Associates: Hillsdale, NJ, USA, 1988.

17. Beidleman, B.A.; Muza, S.R.; Rock, P.B.; Fulco, C.S.; Lyons, T.P.; Hoyt, R.W.; Cymerman, A. Exercise responses after altitude acclimatization are retained during reintroduction to altitude. Med. Sci. Sports Exerc. 1997, 29, 1588-1595. [CrossRef]

18. Fagraeus, L.; Karlsson, J.; Linnarsson, D.; Saltin, B. Oxygen uptake during maximal work at lowered and raised ambient air pressures. Acta Physiol. Scand. 1973, 87, 411-421. [CrossRef]

19. Fulco, C.S.; Rock, P.B.; Trad, L.; Forte, V.; Cymerman, A. Maximal cardiorespiratory responses to one- and two-legged cycling during acute and long-term exposure to 4300 meters altitude. Eur. J. Appl. Physiol. Occup. Physiol. 1988, 57, 761-766. [CrossRef]

20. Koistinen, P.; Takala, T.; Martikkala, V.; Leppäluoto, J. Aerobic fitness influences the response of maximal oxygen uptake and lactate threshold in acute hypobaric hypoxia. Int. J. Sports Med. 1995, 16, 78-81. [CrossRef]

21. Squires, R.W.; Buskirk, E.R. Aerobic capacity during acute exposure to simulated altitude, 914 to 2286 meters. Med. Sci. Sports Exerc. 1982, 14, 36-40. [CrossRef]

22. Wehrlin, J.P.; Hallen, J. Linear decrease in VO2max and performance with increasing altitude in endurance athletes. Eur. J. Appl. Physiol. 2006, 96, 404-412. [CrossRef] [PubMed]

23. Robergs, R.A.; Quintana, R.; Parker, D.L.; Frankel, C.C. Multiple variables explain the variability in the decrement in $\mathrm{VO}_{2 \max }$ during acute hypobaric hypoxia. Med. Sci. Sports Exerc. 1998, 30, 869-879. [PubMed]

24. Benoit, H.; Busso, T.; Castells, J.; Geyssant, A.; Denis, C. Decrease in peak heart rate with acute hypoxia in relation to sea level VO(2max). Eur. J. Appl. Physiol. 2003, 90, 514-519. [CrossRef] [PubMed] 
25. Ferretti, G.; Moia, C.; Thomet, J.M.; Kayser, B. The decrease of maximal oxygen consumption during hypoxia in man: A mirror image of the oxygen equilibrium curve. J. Physiol. 1997, 498, 231-237. [CrossRef] [PubMed]

26. Friedmann, B.; Frese, F.; Menold, E.; Bärtsch, P. Effects of acute moderate hypoxia on anaerobic capacity in endurance-trained runners. Eur. J. Appl. Physiol. 2007, 101, 67-73. [CrossRef]

27. Gavin, T.P.; Derchak, P.A.; Stager, J.M. Ventilation's role in the decline in VO2max and SaO2 in acute hypoxic exercise. Med. Sci. Sports Exerc. 1998, 30, 195-199. [CrossRef]

28. Heubert, R.A.; Quaresima, V.; Laffite, L.P.; Koralsztein, J.P.; Billat, V.L. Acute moderate hypoxia affects the oxygen desaturation and the performance but not the oxygen uptake response. Int. J. Sports Med. 2005, 26, 542-551. [CrossRef]

29. Lawler, J.; Powers, S.K.; Thompson, D. Linear relationship between VO2max and VO2max decrement during exposure to acute hypoxia. J. Appl. Physiol. 1988, 64, 1486-1492. [CrossRef]

30. Martin, D.; O'Kroy, J. Effects of acute hypoxia on the $\mathrm{VO}_{2}$ max of trained and untrained subjects. J. Sports Sci. 1993, 11, 37-42. [CrossRef]

31. Mollard, P.; Woorons, X.; Letournel, M.; Lamberto, C.; Favret, F.; Pichon, A.; Beaudry, M.; Richalet, J.P. Determinants of maximal oxygen uptake in moderate acute hypoxia in endurance athletes. Eur. J. Appl. Physiol. 2007, 100, 663-673. [CrossRef]

32. Ofner, M.; Wonisch, M.; Frei, M.; Tschakert, G.; Domej, W.; Kröpfl, J.M.; Hofmann, P. Influence of acute normobaric hypoxia on physiological variables and lactate turn point determination in trained men. J. Sports Sci. Med. 2014, 13, 774-781. [PubMed]

33. Peltonen, J.E.; Tikkanen, H.O.; Ritola, J.J.; Ahotupa, M.; Rusko, H.K. Oxygen uptake response during maximal cycling in hyperoxia, normoxia and hypoxia. Aviat. Space Environ. Med. 2001, 72, 904-911. [PubMed]

34. Robach, P.; Calbet, J.A.; Thomsen, J.J.; Boushel, R.; Mollard, P.; Rasmussen, P.; Lundby, C. The ergogenic effect of recombinant human erythropoietin on VO2max depends on the severity of arterial hypoxemia. PLoS ONE 2008, 3, e2996. [CrossRef] [PubMed]

35. Pugh, L.G.C.E. Man at High Altitude. J. R. Coll. Physic. Lond. 1969, 3, 385-397.

36. Lenfant, C.; Sullivan, K. Adaptation to high altitude. N. Engl. J. Med. 1971, 284, 1298-1309. [CrossRef]

37. Cerretelli, P. Energy sources for muscular exercise. Int. J. Sports Med. 1992, 13 (Suppl. 1), S106-S110. [CrossRef]

38. Friedmann, B. Training in hypoxia: Detrimental for muscular aerobic capacity? Acta Physiol. 2007, $190,177$. [CrossRef]

39. Mollard, P.; Woorons, X.; Letournel, M.; Lamberto, C.; Favret, F.; Pichon, A.; Beaudry, M.; Richalet, J.P. Determinant factors of the decrease in aerobic performance in moderate acute hypoxia in women endurance athletes. Respir. Physiol. Neurobiol. 2007, 159, 178-186. [CrossRef]

40. Millet, G.P.; Debevec, T. CrossTalk proposal: Barometric pressure, independent of $\mathrm{PO}_{2}$, is the forgotten parameter in altitude physiology and mountain medicine. J. Physiol. 2020, 598, 893-896. [CrossRef]

41. Saugy, J.J.; Rupp, T.; Faiss, R.; Lamon, A.; Bourdillon, N.; Millet, G.P. Cycling Time Trial Is More Altered in Hypobaric than Normobaric Hypoxia. Med. Sci. Sports Exerc. 2016, 48, 680-688. [CrossRef]

42. Ogawa, T.; Fujii, N.; Kurimoto, Y.; Nishiyasu, T. Effect of hypobaria on maximal ventilation, oxygen uptake, and exercise performance during running under hypobaric normoxic conditions. Physiol. Rep. 2019, 7, e14002. [CrossRef]

43. Richard, N.A.; Koehle, M.S. Differences in cardio-ventilatory responses to hypobaric and normobaric hypoxia: A review. Aviat. Space Environ. Med. 2012, 83, 677-684. [CrossRef] [PubMed]

44. Savourey, G.; Launay, J.C.; Besnard, Y.; Guinet, A.; Travers, S. Normo-and hypobaric hypoxia: Are there any physiological differences? Eur. J. Appl. Physiol. 2003, 89, 122-126. [CrossRef] [PubMed]

45. Faiss, R.; Pialoux, V.; Sartori, C.; Faes, C.; Deriaz, O.; Millet, G.P. Ventilation, Oxidative Stress, and Nitric Oxide in Hypobaric versus Normobaric Hypoxia. Med. Sci. Sports Exerc. 2013, 45, 253-260. [CrossRef] [PubMed]

46. Amann, M.; Dempsey, J.A. Ensemble Input of Group III/IV Muscle Afferents to CNS: A Limiting Factor of Central Motor Drive During Endurance Exercise from Normoxia to Moderate Hypoxia. Adv. Exp. Med. Biol. 2016, 903, 325-342. [PubMed]

47. Mourot, L. Limitation of maximal heart rate in hypoxia: Mechanisms and clinical importance. Front. Physiol. 2018, 9, 972. [CrossRef] [PubMed] 
48. Mourot, L.; Millet, G.P. Is Maximal Heart Rate Decrease Similar Between Normobaric Versus Hypobaric Hypoxia in Trained and Untrained Subjects? High. Alt. Med. Biol. 2019, 20, 94-98. [CrossRef] [PubMed]

49. Siebenmann, C.; Rasmussen, P.; Sorensen, H.; Bonne, T.C.; Zaar, M.; Aachmann-Andersen, N.J.; Nordsborg, N.B.; Secher, N.H.; Lundby, C. Hypoxia increases exercise heart rate despite combined inhibition of beta-adrenergic and muscarinic receptors. Am. J. Physiol. Heart Circ. Physiol. 2015, 308, H1540-H1546. [CrossRef]

50. Gavin, T.P.; Stager, J.M. The effect of exercise modality on exercise-induced hypoxemia. Respir. Physiol. 1999, 115, 317-323. [CrossRef]

51. Kalsås, K.; Thorsen, E. Breathing patterns during progressive incremental cycle and treadmill exercise are different. Clin. Physiol. Funct. Imaging 2009, 29, 335-338. [CrossRef]

52. Millet, G.P.; Vleck, V.E.; Bentley, D.J. Physiological differences between cycling and running: Lessons from triathletes. Sports Med. 2009, 39, 179-206. [CrossRef] [PubMed]

53. Netzer, N.C.; Rausch, L.; Eliasson, A.H.; Gatterer, H.; Friess, M.; Burtscher, M.; Pramsohler, S. SpO 2 and Heart Rate During a Real Hike at Altitude Are Significantly Different than at Its Simulation in Normobaric Hypoxia. Front. Physiol. 2017, 8, 81. [CrossRef] [PubMed]

54. Richalet, J.P. CrossTalk opposing view: Barometric pressure, independent of $\mathrm{PO}_{2}$, is not the forgotten parameter in altitude physiology and mountain medicine. J. Physiol. 2020, 598, 897-899. [CrossRef] [PubMed]

(C) 2020 by the authors. Licensee MDPI, Basel, Switzerland. This article is an open access article distributed under the terms and conditions of the Creative Commons Attribution (CC BY) license (http://creativecommons.org/licenses/by/4.0/). 